\title{
The Measurement of Underground Pressure Regulation in Ulan Moron Coal Mine
}

\author{
Guang-Qiao LIN ${ }^{1,2, a}$, Er-Bo SONG ${ }^{1, b,{ }^{*}}$
}

\author{
${ }^{1}$ Faculty of Resources and Safety Engineering, China University of Mining and Technology, Beijing, \\ 100083, China \\ ${ }^{2}$ Materials Management Department of Shenhua Group Corporation Limited, Beijing, 100083, China \\ alingq@shenhua.cc, ${ }^{b} 1547929090 @ q q . c o m$ \\ ${ }^{*}$ Corresponding author
}

Keywords: Underground Pressure, Measurement, Working Face, Analysis.

\begin{abstract}
Based on theoretical research as well as in situ tests, this paper reveals behavior features of mining pressure appearance and the performance of supports for fully mechanized long wall face in Ulan Moron Mine. Depending on systematic analysis of features of working face mine pressure from field tests data, the regular pattern of mine pressure is listed into three stages, which are first weighting, fault-crossing, and end of panel.
\end{abstract}

\section{Introduction}

Ulan Moron Coal Mine belongs to the Shendong Coal Mining Company of Shenhua Group. The mine is located in the town of the Ulan Moron of the Inner Mongolia, and the transportation is convenient. In the south and west of the mine the Basu road and Baofu road through it and in the southwest of mining field Baoshen railway pass by it. It is equipped with the station and the container station of coal in the Battuta. The field's length, from north to south, is about $10 \mathrm{~km}$; and its width, from west to east, is about $6.0 \mathrm{~km}$. The mine area is $44.1045 \mathrm{~km}^{2}$. The approved production of capacity is 7 million ton per annum.

The mine's coal-bearing stratum belongs to the lower Yan'an group of the Jurassic, and the buried depth of coal seam is $70 \sim 200 \mathrm{~m}$. The quality of coal is fine. It belongs to high calorific value of non-stick coal and bituminous coal. It is also the low ash, low sulphur, and low phosphorus. Coal seam occurrence conditions are superior, and its main minable seam has 3 layers. Now it mainly exploits the coal of 1-2 and 3-1, and coal seam gas content is low.

Mine hydro geological conditions are complicated. The mine normal water inflow is $850 \mathrm{~m}^{3} / \mathrm{h}$, and the largest water inflow is $966 \mathrm{~m}^{3} / \mathrm{h}$. The coal seam gas content is low. The results of gas identification in 2009 are that the gas relative gas emission quantity is $0.34 \mathrm{~m}^{3} / \mathrm{t}$, and the absolute gas emission quantity is $4.84 \mathrm{~m}^{3} / \mathrm{min}$. So it is the low gas mine.

The mining coal seam average thickness is $4.6 \mathrm{~m}$ in the 31402 working face. In the early production period, when the first roof is weighting, the crushing accident will happen in the working face because of the large roof weighting intensity. Some stents and parts suffered the different degrees of damage. It affects the normal production of the working face.

\section{The Scheme of Mine Pressure Observation}

In order to master the mine pressure regulation of the 3104 working face, the stents working resistance change of the working face was necessary, which was summarized from the pressure characteristics of the working face [1]. It need to install the monitoring system in the 31402 working face to monitor the stents' working resistance in real time, and then record and transmit the resistance [2,3], then analyse the data [4, $5]$, finally receive the pressure regulation of the working face [6, 7]. Each legs of hydraulic support of the 31402 working face are equipped with a pressure gauge and pressure automatic monitoring system. They can perform the PM311 automatic recording and transmission of data. At the same time, in the 51st, 62nd and the 71st hydraulic support, we install Yolo card to monitor the pressure data. 
It plans to use the yolo card, PM311 and column pressure gauge these three ways to conduct the collection process of measured data, and then organize and analyse the data, and summarize the pressure regulation of the 31402 working face. The observation equipment is shown in figure 1 .

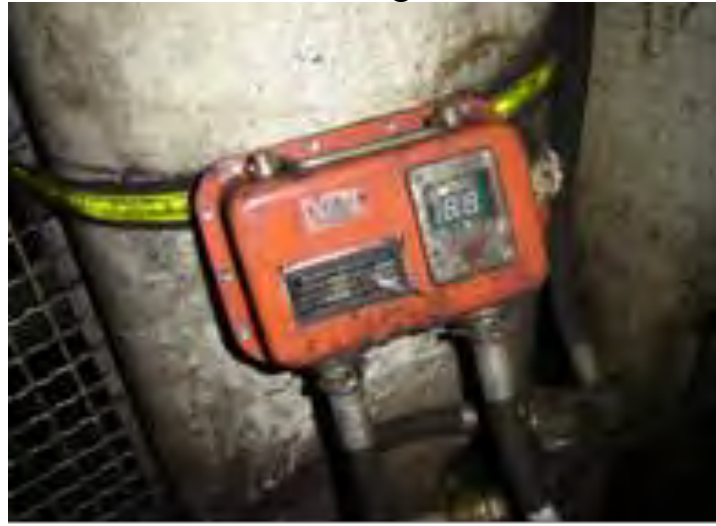

(a) Yolo card

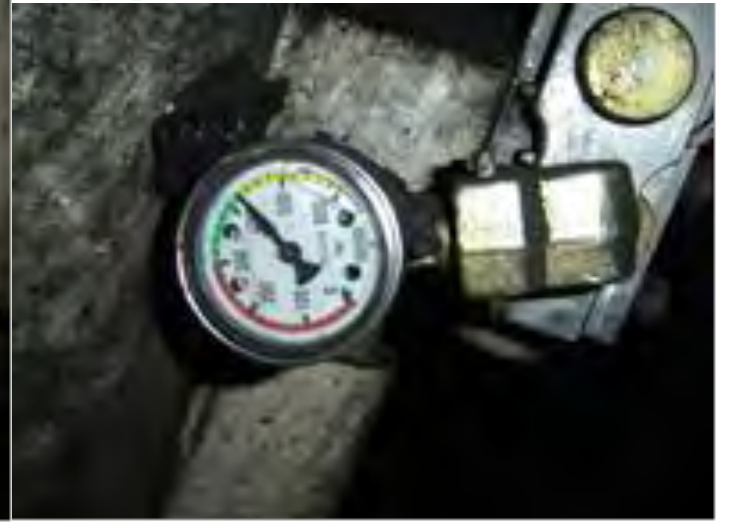

(b) Column pressure gauge

Fig. 1 Mine Pressure Observation Equipment

From the curve, we can see that the support data is rarely available, and only the supports from 50 \# to 70 \# and the end part of the stents are relative availability. Because yolo card data is not corresponding with underground station display data, and pressure gauge's data manual recorded cannot reflect to the pressure condition of the working face, so finally we decide to adopt PM31 data to analyse, and sort out the reasonable part of the supports to analyse, and it is corresponding to the stents $20 \#, 37 \#, 51 \#, 61 \#, 72 \#$, $102 \#$ of the working face.

There is a fault across the all working face in the process of working face advancing, so mine pressure observation time is divided into three stages, and they are respectively corresponding to the early mining stage, through fault stage and at the end of the mining stage.

\section{The Pressure Regulation Analysis in the Early Mining Stage of 31402 Working Face}

\section{The Identification of Measured Data.}

The measured data cannot really reflect the actual situation. From the curve actual measured, as shown in Figure 2 and Figure 3, we can see that whether PM3 1 data or pressure gauge data, there are a lot of pressure that is lower than the stents support setting force, or even to zero or negative, and monitoring instrument is not appeared problem, but the stent itself problems.

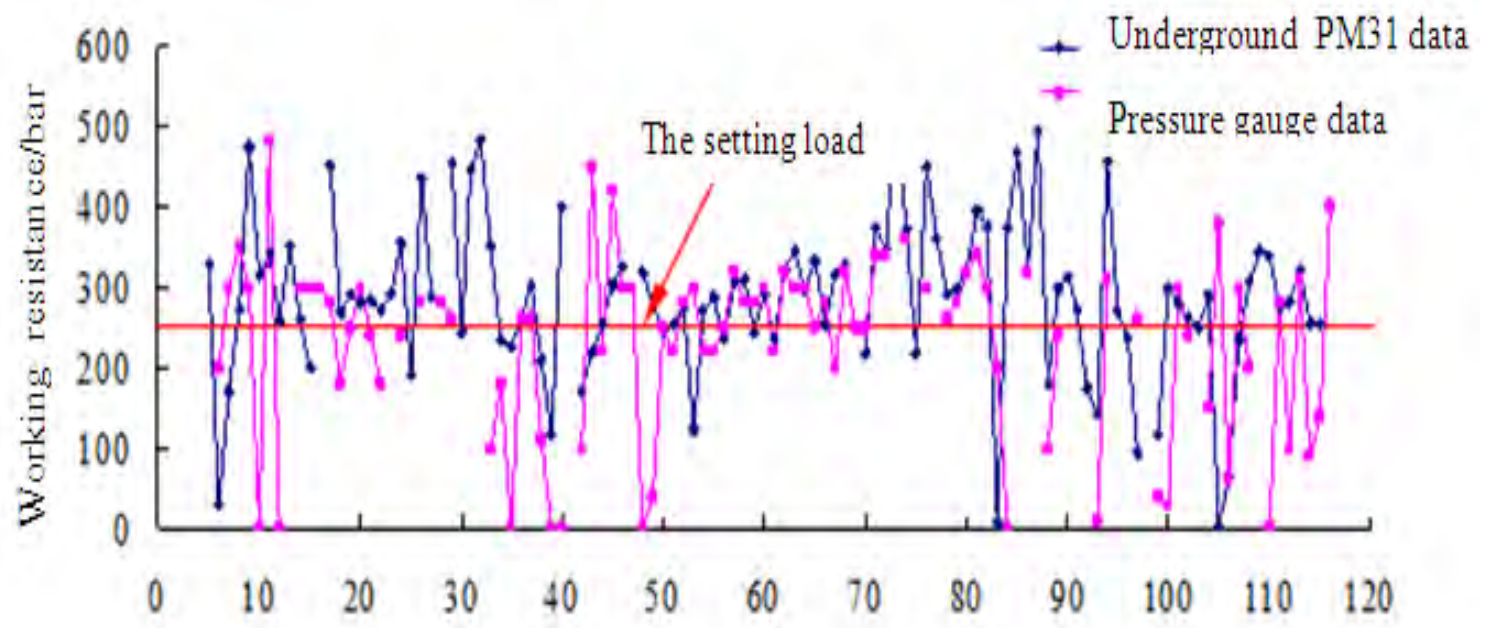

the number of stent stent

Fig. 2 Downhole PM31 and Pressure Gauge Data Contrast Curve 


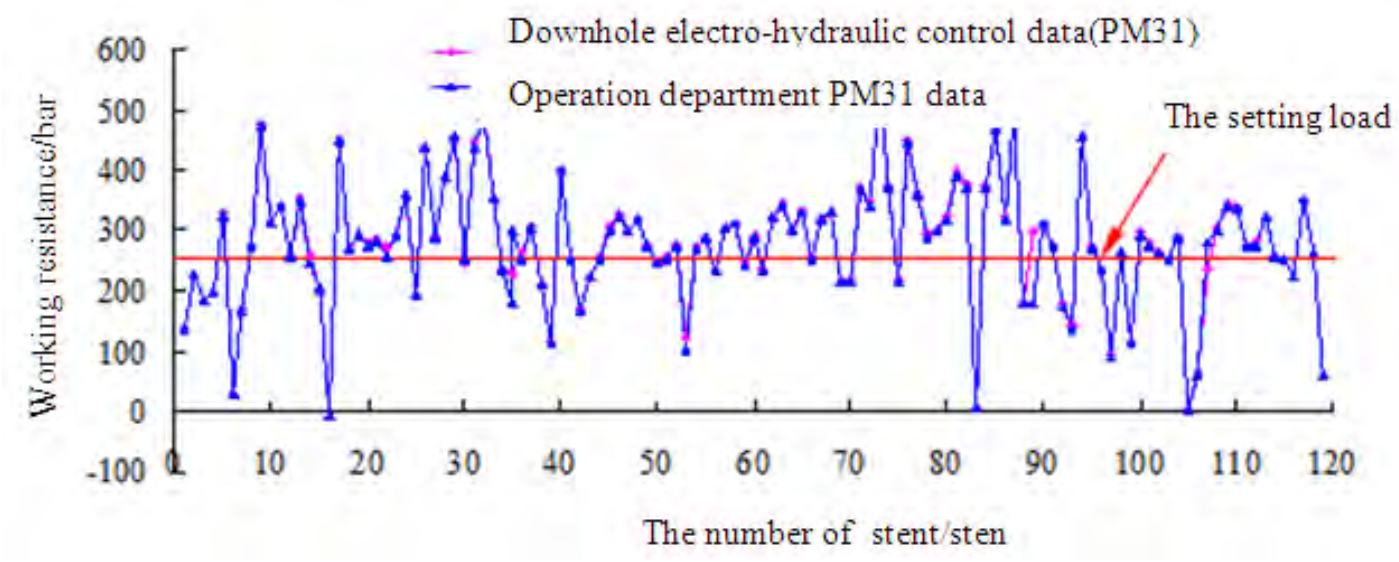

Fig. 3 Downhole Electro-hydraulic Control Data and Receiving Data Contrast Curve

\section{The Pressure Regulation Analysis in the Early Mining Stage of 31402 Working Face}

Based on the above mine pressure observation data and other related information, we can receive conclusions as following:

The roof's first weighting is occurred in the working face advancing to the $35 \mathrm{~m}$ from the open-off cut, the open-off cut's width is $7.5 \mathrm{~m}$, so the roof's first weighting span is $42.5 \mathrm{~m}$.

According to the intensity of 31402 working face's roof first weighting, and the experience of mined working face roof's first weighting span $(40 \sim 55 \mathrm{~m})$ of Ulan Moron Mine 3-1 coal, we can speculate the measures the deep hole's blasting and forced caving has achieved the expected effect, and it does not produce certain destruction to the working face roof.

31402 working face periodic weighting span is $9 \sim 11 \mathrm{~m}$, working face safety production management should be strengthened when happened periodic weighting, and adjust the mining height and reduce the leakage.

31402 working face roof weighting is intense, so suggest slow down the advance speed of the working face before roof weighting, thus gob roof has a process of sinking and fracture. When the working face is advancing to about $25 \sim 30 \mathrm{~m}$, waiting for roof subsidence, releasing part of the pressure, the working face will advance rapidly until having a sign of pressure, to reduce the equipment's damage roof weighting caused.

\section{The Pressure Regulation Analysis in the Through Fault Stage of 31402 Working Face}

In the advance process of the 31402 working face, will meet F62 normal fault, the fault inclined through the whole face, and the influence scope of the working face advance is about $330 \mathrm{~m}$, and it has a great influence on the coal quality and coal mining. So, it is necessary to analysis the pressure regulation of the through fault stage of 31402 working face, which was presented in Figure 4.

Mining height $/ \mathrm{m}$

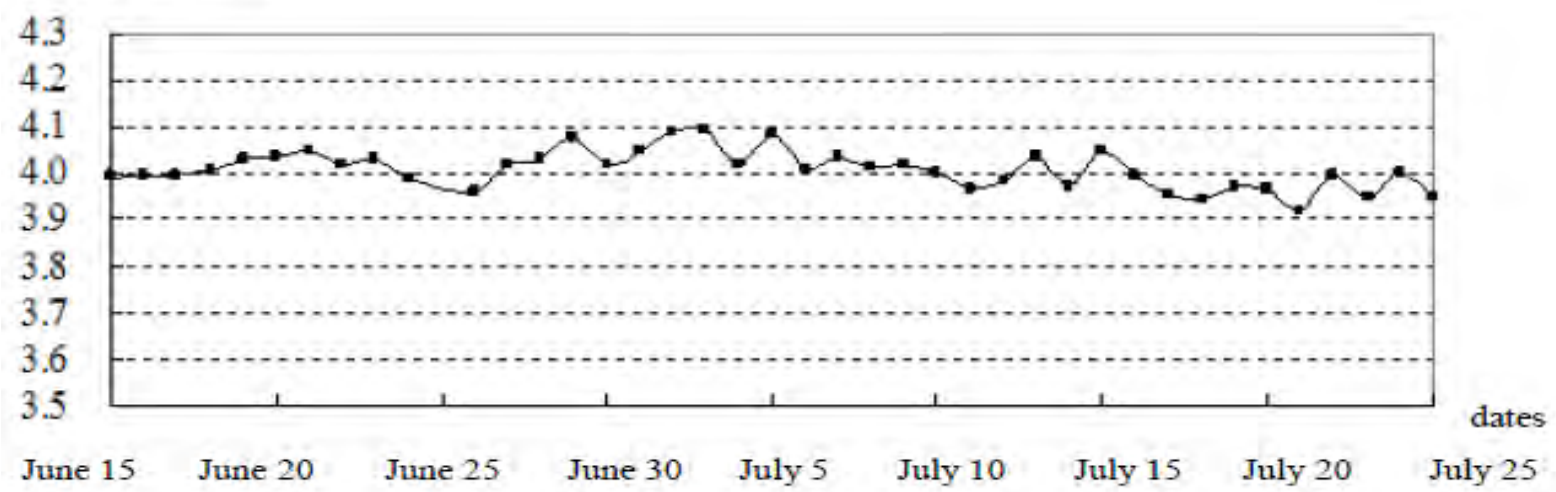

Fig. 431402 Working Face Mining Height is Broken during the Fault Distribution 
As shown in Figure 4, the tail side statistical data of the 102\# stent shows that, the working face weighting span is $9.8 \sim 19.28 \mathrm{~m}$, and the average weighting span is $13.7 \mathrm{~m}$; the weighting sustained length is $0.8 \sim 2.4 \mathrm{~m}$, and the average is $1.2 \mathrm{~m}$; during the weighting, the stents' cyclic last resistance is $390 \sim 438$ bar, and the average is $421 \mathrm{bar}(8570 \mathrm{KN})$, and the normal resistance is $276 \sim 306$ bar, average is 293 bar(5964 KN). The dynamic load coefficient is $1.35 \sim 1.57$, the average is 1.44 .

By contrast the various regions pressure characteristics of the table 4-2 can be found, the weighting span of the working face both end is bigger than the central apparently, and the load of the stents is less than the central; the tail weighting sustained length is minimum, the nose side and the middle part are not much difference; the dynamic load coefficient of different area is same, and each of them is around 1.45. From the working resistance of the stents' pressure, it is not hard to know the load is beyond the stents rated resistance $(9000 \mathrm{KN})$, and it explains that the stents' working resistance is not enough, and it still need to further enhance.

On July 20,31402 working face is fully through the fault affect area, in the advancing process, mining height is basic between 3.9 4.1 $\mathrm{m}$ in control, the average is $4.0 \mathrm{~m}$ (As shown in figure 4-8). Being affected by the fault, the working face situation is fine ,though partly rib spall, and there is not the leakage phenomenon. Because the fault influence area is mainly located in the nose side, and the rock mass of fault surface is not broken completely, at the same time the working face can remove the stents and open the face guard in time, and the roof support management is in place, thus the fault does not bring great influence to normal production of working face, also does not have a phenomenon that pressure increased, safety valve opening and drainage, and a phenomenon of the obvious dynamic load mine pressure and rock-burst.

\section{The Pressure Regulation Analysis at the End of Mining Stage of the Working Face}

\section{The Pressure Forecast of the Ulan Moron Mine 31402 Working Face Retracement stages}

When the working face through connection, roof weighting or not directly related to the quality of and the safety of the retreat stents. So in order to avoid the roof weighting, we make a particular prediction to the pressure situation of the working face retracement stage, and use the results of the prediction to adjust the working face advancing speed, and realize the no-pressure through connection of the working face.

Through the analysis of the working face support pressure curve, in the statistical process, found that the changes of the working face weighting span is along with the advancing speed, when the advancing speed is $5.8 \mathrm{~m} / \mathrm{d}$, the average weighting span is $8.5 \mathrm{~m}$; when the advancing speed is $9.5 \mathrm{~m} / \mathrm{d}$, the average weighting span is $9.7 \mathrm{~m}$.

Through the recent weighting span can predict the location of the working face period pressure in the future of 2 3 times. Due to the discreteness of weighting span the change of the geological and mining technical conditions caused, it may have a large difference with the real to forecast the period pressure location according to the weighting span, so it is only for reference.

The average weighting span of the first two working face is $10 \mathrm{~m}$, therefore it is expected to face again pressure, corresponding forward advancing position that distances retracement channel $12.9 \mathrm{~m}$. Now, The working face will enter the hanging net and mining coal stage, and then advance speed will be reduce to an average of $4 \mathrm{~m} / \mathrm{d}$, corresponding the weighting span will be less.

The best roof weighting situation when working face is through connecting is that the working face is just breakthrough at the end of the roof weighting. According to the statistical results of the near retracement stage's pressure characteristic, the sustain pressure length is $2.3 \mathrm{~m}$, so the best pressure position distances the retracement channel $2.3 \mathrm{~m}$.

However, according to the predicting results of the pressure position, when the working face is breakthrough, the pressure position distances retracement channel $4.4 \mathrm{~m}$, and it is greater than the above best pressure position. In the hanging net and mining coal stage, the working face advancing speed should not be too low, thus prevent the decrease of the weighting span and the missing best pressure position. 


\section{The Pressure was Observed in Ulan Moron Mine 31402 Working Face during Retracement Stage}

Similar to the through fault stage, the different phenomenon characteristic of underground pressure is presented in the face side, the central part and the tail side.

The end of mining stage's pressure regulation is same with the first, both of then present the characteristics that the ends' weighting span is apparently greater than the central. The end of mining stage stents support load is slightly larger than the fault stage, but dynamic load factor is lower, and it is about 1.4. The stents load of all regions except the side of tail is beyond the stents rated resistance $(9000$ $\mathrm{KN}$ ), and it explains that the stents working resistance is not enough, and it still need to further enhance.

\section{Conclusion}

Contrasting the PM311, pressure gauge and yolo card data, finally the 6 reasonable data of the working face middle part and the end part are chosen to analyse.

The first roof weighting is intense, and the damage to the stents is serious, the $67 \#$ stent shield-beam is broken, and another nine stent balance cylinder is damaged, the ear of the 7 stents balance cylinder damaged.

When the 31402 working face through the fault, the working face does not present the abnormal pressure phenomenon, and the roof weighting is normal.

In the end of the 31402 working face mining stage, when the working face is breakthrough, the roof does not appear the weighting phenomenon, and the quality of the breakthrough is fine, and the working face stents and equipment are safe retreated.

\section{Acknowledgement}

This project was partially supported by the Fundamental Research Funds for the Central Universities (No.2010QZ02), the Funds of State Key Laboratory of Coal Resources and Safe Mining (China University of Mining and Technology)( No.SKLCRSM11KFB05), and the National Natural Science Foundation - Shenhua Group, Coal Joint Fund(NO.U1361209).

\section{References}

[1]Wilson A N. A hypothesis concerning pillar stability. Mining Engineer, 6(1972) 85-90.

[2]Whittaker B N. Design and stability of pillar in long wall mining. Mining Engineer, 13 (1979) 68-72.

[3]Wu J, Meng XR, Jiang YD. Development of longwall top-coal caving technology in China. In: Proceedings of the international workshop on underground thick-seam mining. 6 (1999) 101-12.

[4]Alehossein H, Poulsen BA. Stress analysis of longwall top coal caving. Int. J Rock Mech. Min Sci. 47 (2010) 30-41.

[5]Simsir F, Ozfirat MK. Determination of the most effective longwall equipment combination in longwall top coal caving (LTCC) method by simulation modeling. Int. J Rock Mech. Min Sci. 45 (2008) 1015-1023.

[6]Xie GX, Chang JC, Yang K. Investigations into stress shell characteristics of surrounding rock in fully mechanized top-coal caving face. Int. J Rock Mech. Min Sci. 46 (2009)172-181.

[7]Wang JA, Park HD. Coal mining above a confined aquifer. Int. J Rock Mech. Min Sci. 40 (2003)537-551. 